\title{
Optimal Allocation of Capacitor for Iraqi Distribution Network using FLC-PSO Controller
}

\author{
Afaneen Anwar Abbood \\ Asst. professor, \\ Electrical Engineering Dep. \\ Faculty of Enginnering, \\ University of Technology, \\ Baghdad, Iraq
}

\author{
Abbas Kadhim Dhaher \\ Master Student Course \\ Electrical Engineering Dep. \\ Faculty of Enginnering, \\ University of Technology, \\ Baghdad, Iraq
}

\begin{abstract}
The aim of this work is obtaining the optimal power flow for the Iraqi distribution network represented by AlRUSTAMIYA_Feeder09, through adding the capacitors to the system in order to reach the best improvement of voltage profile and power losses reduction. . A Fuzzy Logic (FLC)Particle Swarm Optimization (PSO) controller was proposed to detect the optimal location and size of the capacitor banks in electrical distribution system. Three load variation levels were considered during the study those are $60 \%, 80 \%$, and $100 \%$ load variation. From the obtained results it was very clear that the proposed intelligent algorithm was very accurate and efficient for obtaining the optimal location and size of the capacitors in the system.
\end{abstract}

\section{Keywords}

Reactive power control; Capacitor Placement and Sizing; FLC-PSO Approach, Iraqi distribution network

\section{INTRODUCTION}

The power supplied from electrical distribution system is composed of both active and reactive components. Overhead lines, transformers and loads consume the reactive power. The distribution network is always suffering from load demand growing; this lead to increase the burden on the power system and reduces the voltage levels. In order to improve the efficiency of any power system, the losses at the distribution level must be reduced. The reactive power control will improve the voltage profile, reduces the system losses and improves the system efficiency.

Many solutions have been used to reduce these losses and improves the voltage profiles such as network reconfiguration, installing shunt capacitor, voltage regulators placement, etc. In this work, locating the optimal location and size of capacitors were considered for achieving voltage profile improvement and losses reduction in the distribution system.

Even though considerable amount of research work was done in the area of optimal capacitor placement [2 to 13], there is still a need to develop more suitable and effective methods for the optimal capacitor placement.

In this work, a controller combining two intelligent algorithms FLC-PSO was proposed. The FLC algorithm provides a remedy for any lack of uncertainty in the data. It has the advantage of including heuristics and representing engineering judgments into the optimal capacitor placement problem, so the solutions from this approach can be easily analyzed to determine optimal capacitor locations. On the other hand, PSO algorithm is more useful in obtaining the optimal capacitor sizes. The proposed FLC-PSO controller was implemented on Iraq practical rural 62-node distribution system. Fixed capacitors were used because they are already installed in Iraqi distribution system.

\section{PROBLEM FORMULATION}

Shunt capacitor banks connected to a power system are the most economical source to meet the reactive power requirement of inductive loads and transmission lines operating at lagging power factor. By using shunt capacitor, the magnitude of the source current can be reduced; the power factor improved, and reduce the voltage drop between the sending end and the load end. The main problem of capacitor placement is to determine the location, type, and size of capacitors to be placed on a system, the problem includes the following inserting constraints:

\section{Bus Voltage Limits:}

The bus voltage magnitudes are to be kept within acceptable operating limits throughout the optimization process:

$$
V_{\min .} \leq\left|V_{i}\right| \leq V_{\max }
$$

2. The number and sizes of permissible capacitor banks constraint:

The number of capacitor banks can be expressed to satisfy the following expression:

$\sum_{i=1}^{m} Q_{c} \leq Q_{t}$

3. The line current (I) should be less than the line rated current (Irated).

$\mathrm{I} \leq \mathrm{I}_{\text {rated }}$

4. Power losses after the capacitor placement must less or equal to Power losses before the capacitor placement

$\mathrm{P}_{\text {loss }(\mathrm{q}+1)} \leq \mathrm{P}_{\text {loss }(\mathrm{q})}$

Where:

$\mathrm{P}_{\text {loss }(\mathrm{q}+1)}$ : Power losses after the capacitor placement

$\mathrm{P}_{\text {loss (q) }}$ : Power losses before the capacitor placement

The total $\mathrm{I}^{2} \mathrm{R}$ losses (PL) for a distribution system with $\mathrm{n}$ number of branches is given by:

$P_{L}=\sum_{i=1}^{n} I_{i}^{2} R_{i} \quad \ldots \ldots . .5$

Where $I_{i}$ is the magnitude of the branch current. $R_{i}$ is the resistance of the $i^{\text {th }}$ branch. Since the branch current has two components $I_{a}$ and $I_{r}$, then the losses of the active and reactive components of the current can be calculated as:

$P_{L a}=\sum_{i=1}^{n} I_{a i}^{2} R_{i} \quad \ldots \ldots .6$ 
$P_{L r}=\sum_{i=1}^{n} I_{r i}^{2} R_{i} \quad \ldots \ldots 7$

Where PLa associated with the active component of branch currents, PLa cannot be reduced because all active power must be supplied by the source at the root bus, supplying part of the reactive power demand locally can minimize the loss PLr associated with the reactive component of branch currents. The estimation of candidate nodes to place the capacitors helps in reduction in the search space for the optimization procedure, Power Losses Indices method is used for capacitors placement.

Capacitors can be placed on the nodes with the highest suitability. A load flow solution for the original system is required to obtain the initial real and reactive power losses. By compensating the total reactive load at every node of the distribution system, the power loss reduction is obtained using the load flow program. The loss reductions are then, linearly normalized into a (0-1) range with the largest loss reduction having a value of 1 and the smallest one having a value of 0 ,

The power Loss Index value for nth node was calculated using the equation:

$$
\begin{aligned}
& \operatorname{PLI}(n) \\
& =\frac{(\text { Losses reduction }(n)-\text { Losses reduction }(\min ))}{(\text { Losses reduction }(\max )-\text { Losses reduction }(\min )} \ldots
\end{aligned}
$$

\section{THE PROPOSED INTELLIGENT CONTROLLER}

The main benefit of the intelligent methods is their flexibility for handling different qualitative limitation. These methods can obtain several optimal solutions by doing a single simulation run. Therefore, they are relatively suitable for overcoming optimization problems. The techniques are in general based on biologically inspired strategies for solving problems. In this work, a combined FL-PSO controller is used to obtain optimal placement and sizing for the Iraqi distribution system. Figure (1) shows a block diagram for the proposed FLC-PSO.

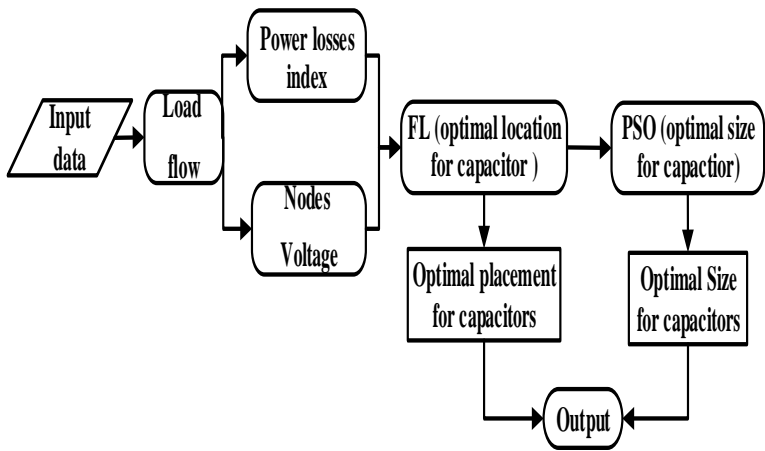

Figure (1) Block diagram of intelligent FL-PSO approach

As shown from the figure, the controller contains two parts, the FLC and the PSO part. Two objectives are considered in designing the FLC approach for identifying the optimal capacitor locations, those are: (i) minimize the real power loss. (ii) Maintain the voltage within the permissible limits.

The voltages and the power loss indices of the system nodes under consideration are modeled by fuzzy membership functions. The set of rules are then used to determine the capacitor placement suitability of each node in the distribution system.
The power loss reduction indices along with the p.u. nodal voltages were the inputs for the FLC, which determines the suitable node for capacitor installation. Two input and one output variables are selected. The first input variable is the power loss index (PLI) and the second one is the per unit nodal voltage (V).The output variable is the Capacitor suitability Index (CSI). Power Loss Index range varies from 0 to 1 , P.U. nodal voltage range varies from 0.88 to 1.1 and Capacitor Suitability Index range varies from 0 to 1 .

Five membership functions are selected for PLI. Those are: L, $\mathrm{LM}, \mathrm{M}, \mathrm{HM}$ and $\mathrm{H}$. All the five membership functions are triangular as shown in Figure (2), for the selected voltage: L, $\mathrm{LN}, \mathrm{N}, \mathrm{HN}$ and $\mathrm{H}$. These membership functions are trapezoidal and triangular as shown in Figure (3) and for the CSI are: L, LM, M, HM and $\mathrm{H}$, the membership functions are triangular also. See figure (4)

For determining the suitability of capacitor placement at a particular node, a set of multiple-antecedent fuzzy rules has been established. The rules are summarized in the fuzzy decision matrix in Table-1. The consequents of the rules. Optimal capacitor locations are identified based on the highest Capacitor Suitability Index values.

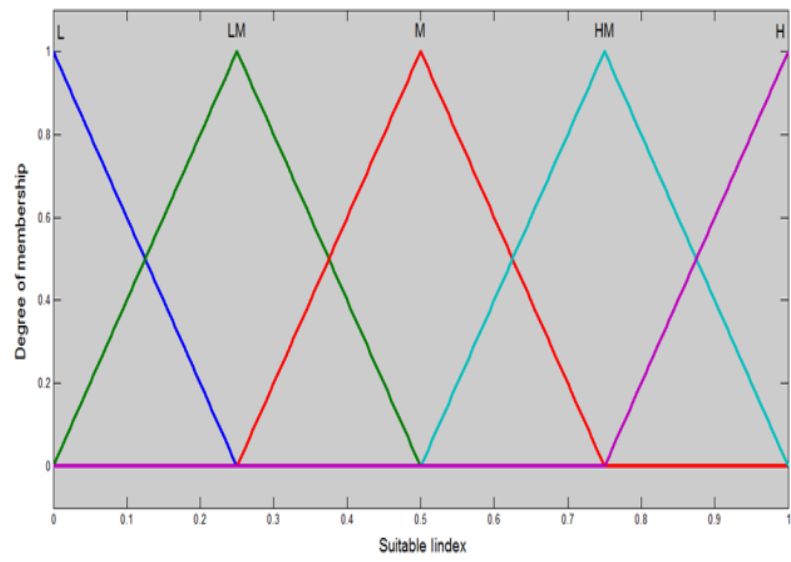

Figure-2. Membership function plot for P.L.I

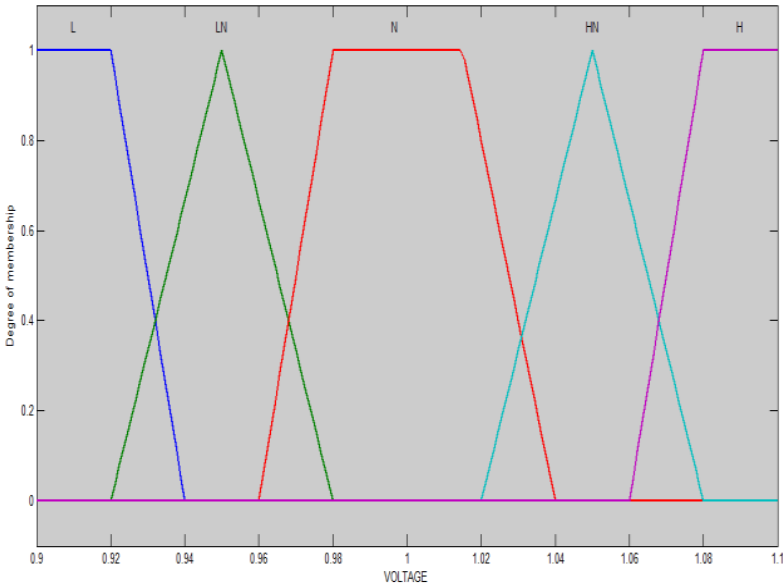

Figure-3. Membership function plot for p.u. nodal voltage 


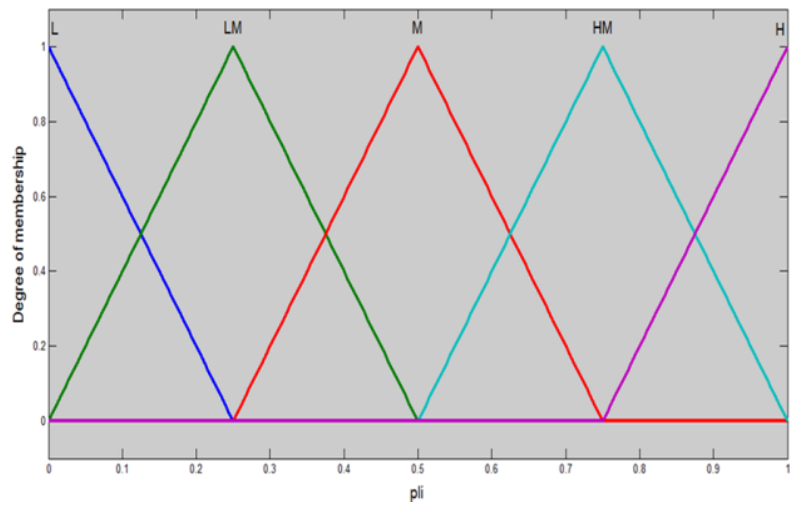

Figure-4. Membership function plot for C.S.I.

Table-1. Decision matrix for determining the optimal capacitor locations.

\begin{tabular}{|c|c|c|c|c|c|c|}
\hline \multicolumn{2}{|c|}{} & L & LN & N & HN & H \\
\hline \multirow{4}{*}{ PLI } & L & LM & LM & L & L & L \\
\cline { 2 - 7 } & LM & M & LM & LM & L & L \\
\cline { 2 - 7 } & M & HM & M & LM & L & L \\
\cline { 2 - 7 } & HM & HM & HM & M & LM & L \\
\cline { 2 - 7 } & H & H & HM & M & LM & LM \\
\hline
\end{tabular}

For calculating the optimal size of the inserted capacitor, the PSO was used were the swarm consists of individuals called particles. Each particle in the swarm represents a potential solution of the optimization problem. Each particle moves through a D-dimensional search space at a random velocity. Each particle updates its velocity and position according to the following equations:

$v_{j+1}^{i}=v_{j}^{i}+c_{1} r_{1}\left(p_{j}^{i}-x_{j}^{i}\right)+c_{2} r_{2}\left(p_{j}^{g}-x_{j}^{i}\right) \quad j=1, . . n \quad \ldots 9$

$x_{j+1}^{i}=x_{j}^{i}+v_{j+1}^{i} \quad j=1, \ldots, n$

\section{Where}

$\mathrm{c}_{1}$ and $\mathrm{c}_{2}$

$r_{1}$ and $r_{2}$

$\mathrm{p}_{\mathrm{j}}^{\mathrm{i}}$

$p_{j}^{g}$

are acceleration constants; are uniformly distributed random numbers In the range 0 and 1.

$\rho_{j}^{i}$ Best position ever visited by the Particle at the $i$ th iteration;

Global best position in the entire swarm;

\section{THE STRUCTURE OF THE PROPOSED PROGRAM}

Step1: schedule PLI for capacitor and Voltage in per unit. Step2: Set the PLI as input1 and the per-unit voltage as input2

Step3: Fuzzified the inputs at Fuzzification unit.

Step4: Fuzzified Inputs process at Fuzzy logic-reasoning unit Step5: deffuzzified Fuzzy controller outputs to classify the suitable Index (SI). The nodes, which have the greatest value of CSI, will be appropriate for placing the capacitor. Output of FLC is input for PSO determine the optimal size.
Step6: Read capacitors standard sizes.

Step 7: Generate particle swarm.

Step 8: Define the fitness of each particle swarm as the minimum total losses in the system.

Step 9: Check and modernize personal and global bests according to the Optimal size of capacitors that satisfy the objective function of minimum losses and voltage improvement.

Step 10: Update each individual velocity and position.

Step 11: Check stopping criteria, which are:

1. Voltage limits.

2. $\mathrm{QT}<\mathrm{QC}$.

3. Line losses after adding capacitor $<$ line losses before adding capacitor.

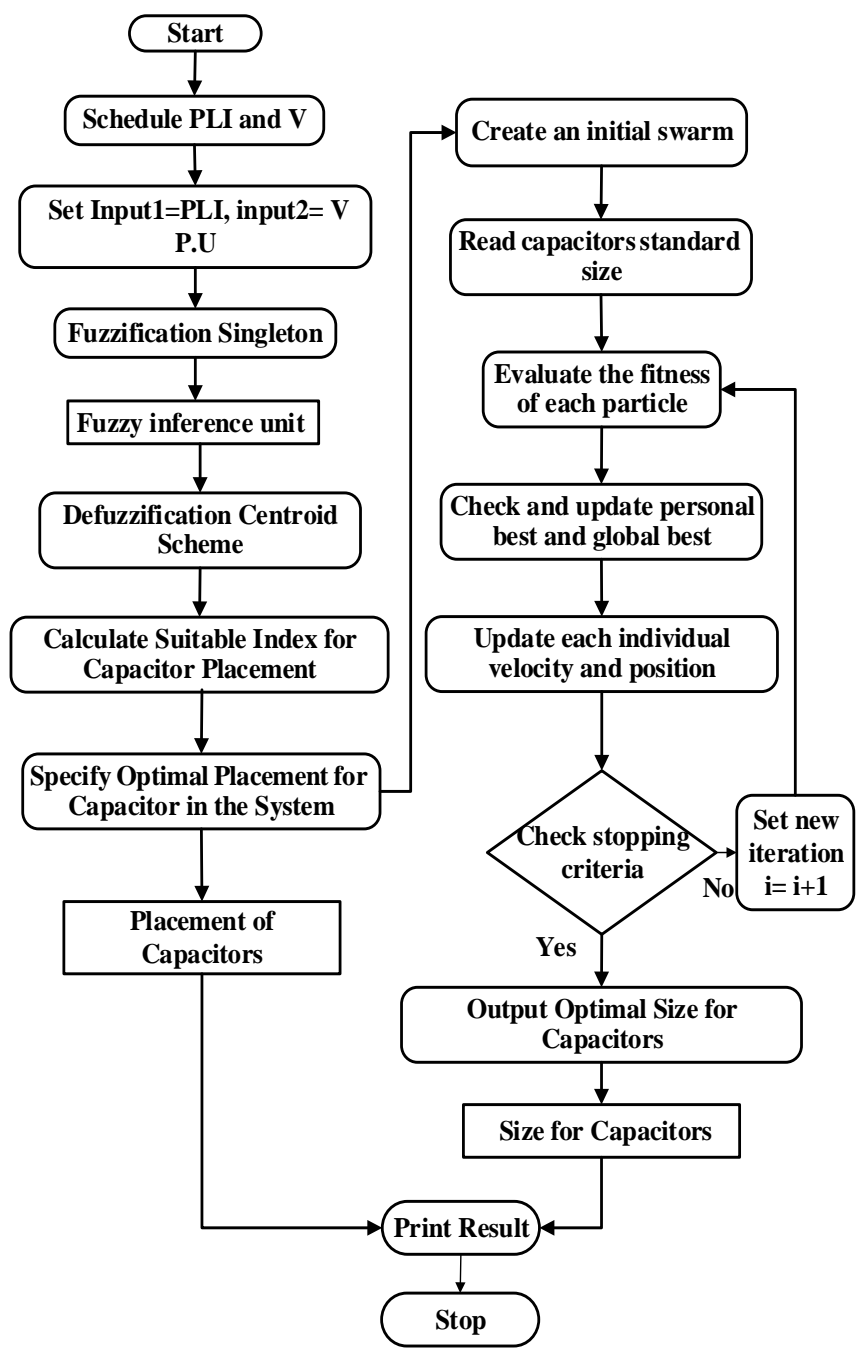

Figure (5) the flow chart of the proposed algorithm

\section{RESULT AND DISCUSSION}

The proposed intelligent FLC-PSO controller was implemented on the Iraqi distribution system represented by Al- RUSTAMIYA_Feeder09, $11 \mathrm{kv}, 50 \mathrm{~Hz}, 62$ nodes single source, figure (6) shows the one line diagram of the distribution system under consideration. The voltage limits were selected as Vmin $=0.95 \mathrm{pu}$ and $\mathrm{Vmax}=1.05 \mathrm{pu}$. Three load variation were considered in this study 60,80 and $100 \%$ and since the $80 \%$ load variation covers the longest period of 
the load cure of the system under consideration, then it was considered in the calculations of the optimal location and size of capacitors for the system. The input data represents the annual load curve for the system for the year 2014. See the appendix A.

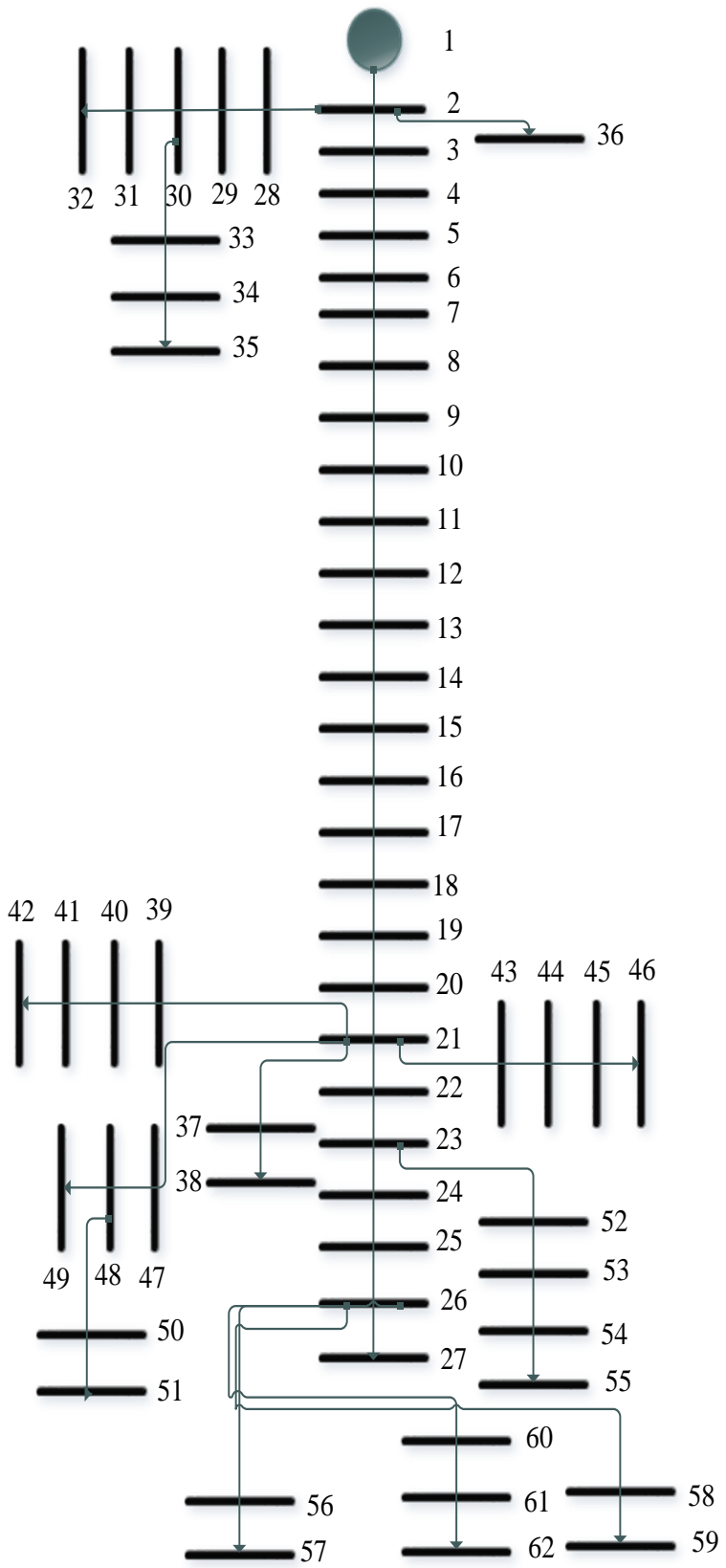

Figure (6) Al- RUSTAMIYA_Feeder09 distribution system

Table (2) shows the optimal locations of capacitor which have capacitor suitable index (CSI) more than 0.75 using FLC, and optimal size of capacitors using PSO. Table (3) show the real and reactive power losses before and after the installation for the Three-load variation.
Table (2) the optimal sizes of capacitor

\begin{tabular}{|c|c|}
\hline Location by FES & Size by PSO-KVAR \\
\hline 24 & 1200 \\
\hline 39 & 600 \\
\hline 52 & 450 \\
\hline Total sizes & 2250 \\
\hline
\end{tabular}

Table (3) losses and voltage after and before capacitors

\begin{tabular}{|c|c|c|c|}
\hline $\mathbf{1 0 0 \%}$ & Before & After & Improve\% \\
\hline KW loss & 411.37 & 248.6174 & 39.563 \\
\hline KVAR loss & 409.28 & 246.8701 & 39.681 \\
\hline Min voltage & 0.88532 & 0.9318 & 5.25 \\
\hline $\mathbf{8 0 \%}$ & Before & After & \\
\hline KW loss & 250.6816 & 149.5314 & 40.35 \\
\hline KVAR loss & 249.3294 & 148.6792 & 40.368 \\
\hline Min voltage & 0.9104 & 0.9539 & 4.8 \\
\hline 60\% & Before & After & \\
\hline KW loss & 159.8883 & 98.6114 & 38.324 \\
\hline KVAR loss & 158.9907 & 98.3128 & 38.164 \\
\hline Min voltage & 0.9284 & 0.9699 & 4.47 \\
\hline
\end{tabular}

Figures (7, 8. And 9) shown in appendix B show that the voltage, the real power losses, and the reactive power losses improvement at $80 \%$ load level respectively. The red curve represents the base case and the blue one represents the vales after adding the capacitors.

The execution time for FLC-PSO is 21.571947 seconds.

From the tables it is clear that adding the capacitors reduces the real losses, reactive losses and improves the voltage profile by (38.324\% -to- $39.563 \%)(38.164 \%-39.681 \%)$ and $(4.47 \%-5.25 \%)$ respectively for the three cases $(60 \%-100 \%)$ of the load variation.

\section{CONCLUSION}

This paper introduced an intelligent FLC-PSO approach method to determine the optimal location and size of capacitors in Iraqi distribution power system. This combination reduced active power losses and improved the bus voltage levels in an efficient way .The main advantage of this approach was clarifying the robustness of intelligent systems over the conventional systems in flexibility, robustness of the complex combination problem, sure and fast convergence. The obtained results declared the effectiveness of the proposed method.

\section{REFERENCES}

[1] D. Das .1994. Novel method for solving radial distribution networks IEEE, 1994 Paper 9966C

[2] Duran H. 1968. Optimum number, location and size of shunt capacitors in radial distribution feeders: A dynamic programming approach. IEEE Transactions on Power Apparatus and Systems. 87(9): 1769-1774 September. 
[3] Bae Y.G. 1978. Analytical method of capacitor allocation on distribution primary feeders. IEEE Transactions on Power Apparatus and Systems. PAS97(4): 1232-1238, July.

[4] Grainger J.J and S.H. Lee. 1981. Optimum size and location of shunt capacitors for reduction of losses on distribution feeders. IEEE Transactions on Power Apparatus and Systems. PAS-100(3): 1105-1118, March.

[5] Baran M.E. and Wu F.F. 1989. Optimal capacitor placement on radial distribution systems. IEEETransactions on Power Delivery. 4(1): 725-734 January.

[6] Baran M.E. and Wu F.F. 1989. Optimal sizing of Capacitors placed on a radial distribution system. IEEE Transactions on Power Delivery. 4(1): 735743, January.

[7] Sundhararajan S. and Pahwa A. 1994. Optimal selection of capacitors for radial distribution systems using a genetic algorithm. IEEE Transactions on Power Systems. 9(3): 1499-1507, August.

[8] Chis M., Salama M.M.A. and Jayaram S. 1997.Capacitor placement in distribution systems using heuristic search strategies. IEE proceedings onGeneration, Transmission and Distribution. 144(3): 225-230, May.

[9] Haque M.H. 1999. Capacitor placement in radial distribution systems for loss reduction. IEE Proceedings on Generation, Transmission and Distribution. 146(5): 501-505, September.

[10] Ng H.N., Salama M.M.A. and Chikhani A.Y. 2000. Capacitor allocation by approximate reasoning: fuzzy capacitor placement. IEEE Transactions on Power Delivery. 15(1): 393-398, January.

[11] Prakash K. and Sydulu M. 2007. Particle swarm optimization based capacitor placement on radial distribution systems. IEEE Power Engineering Society general meeting. pp. 1-5, June.

[12] M. Damodar Reddy and V.C. Veera Reddy. 2008. Optimal capacitor placement using fuzzy and real coded genetic algorithm for maximum savings. Journal of Theoretical and Applied Information Technology. 4(3): 219-226.

[13] M. Damodar Reddy and V.C. Veera Reddy. 2008 Capacitor placement using fuzzy and particle swarm optimization method for maximum annual savings. ARPN Journal of Engineering and Applied Sciences. 3(3): 25-30.

[14] Timothy J. Ross "FUZZY LOGIC WITH ENGINEERING APPLICATIONS" Book University of New Mexico, USA, 2004.

[15] James Kennedy and Russell Eberhart "Particle Swarm Optimization" book, IEEE 1995.

\section{APPENDIX A}

\begin{tabular}{|c|c|c|c|c|c|c|c|}
\hline \multicolumn{8}{|c|}{$\mathrm{V}=11 \mathrm{KV} \quad$ P.F. $=0.8$} \\
\hline \multicolumn{8}{|c|}{ LINE DATA } \\
\hline \multicolumn{3}{|c|}{ Node data } & \multicolumn{5}{|c|}{ 11kV Feeder data } \\
\hline \multirow{19}{*}{$\begin{array}{l}\text { Main } \\
\text { feeder }\end{array}$} & $\begin{array}{l}\text { Node } \\
\text { No. }\end{array}$ & $\begin{array}{l}\text { Trans. } \\
\text { Rating } \\
\text { (kVA) }\end{array}$ & $\begin{array}{l}\text { Feeder } \\
\text { section }\end{array}$ & $\begin{array}{l}\text { Kind of } \\
\text { feeder }\end{array}$ & Length $(\mathrm{km})$ & $\mathrm{R}(\Omega)$ & $\mathrm{X}(\Omega)$ \\
\hline & 2 & - & s.s-2 & $\begin{array}{c}3 \times 150 \\
\text { UGC }\end{array}$ & 2.133 & 0.29464 & 0.230703 \\
\hline & 3 & 400 & $2-3$ & Al-95 & 0.1 & 0.04184 & 0.044302 \\
\hline & 4 & 250 & $3-4$ & Al-95 & 0.216 & 0.03146 & 0.03331 \\
\hline & 5 & 250 & $4-5$ & Al-95 & 0.216 & 0.06795 & 0.07194 \\
\hline & 6 & 250 & $5-6$ & Al-95 & 0.15 & 0.06795 & 0.07194 \\
\hline & 7 & 250 & 6-7 & Al-95 & 0.15 & 0.04719 & 0.049965 \\
\hline & 8 & 250 & $7-8$ & Al-95 & 0.066 & 0.04719 & 0.049965 \\
\hline & 9 & 250 & $8-9$ & Al-95 & 0.466 & 0.020763 & 0.021984 \\
\hline & 10 & 250 & $9-10$ & Al-95 & 0.266 & 0.146603 & 0.155224 \\
\hline & 11 & 250 & $10-11$ & Al-95 & 0.233 & 0.083683 & 0.088604 \\
\hline & 12 & 250 & $11-12$ & Al-95 & 0.183 & 0.073301 & 0.077612 \\
\hline & 13 & 250 & $12-13$ & Al-95 & 0.3 & 0.05757 & 0.06095 \\
\hline & 14 & 250 & 13-14 & Al-95 & 0.133 & 0.09438 & 0.09993 \\
\hline & 15 & 250 & $14-15$ & Al-95 & 0.066 & 0.041841 & 0.044302 \\
\hline & 16 & 250 & $15-16$ & Al-95 & 0.266 & 0.020763 & 0.02198 \\
\hline & 17 & 250 & $16-17$ & Al-95 & 0.5 & 0.020763 & 0.02198 \\
\hline & 18 & 250 & $17-18$ & Al-95 & 0.4 & 0.1573 & 0.16655 \\
\hline & 19 & 250 & $18-19$ & Al-95 & 0.166 & 0.12584 & 0.13324 \\
\hline
\end{tabular}




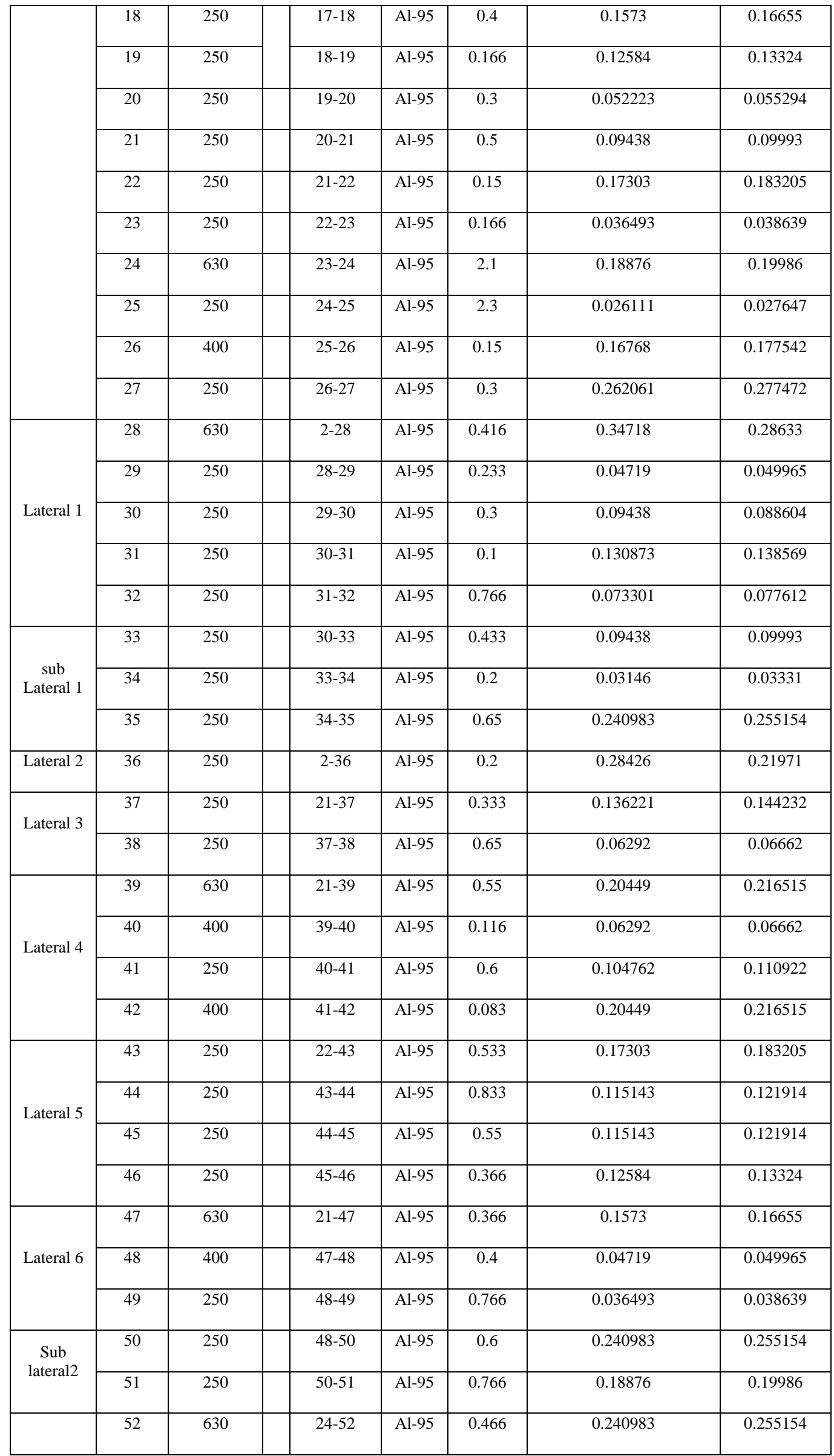




\begin{tabular}{|c|c|c|c|c|c|c|c|c|}
\hline Lateral 7 & 53 & 400 & & $52-53$ & Al-95 & 0.266 & 0.146603 & 0.155224 \\
\cline { 2 - 8 } & 54 & 250 & & $53-54$ & Al-95 & 0.8333 & 0.083683 & 0.088605 \\
\hline
\end{tabular}

\begin{tabular}{|c|c|c|c|c|c|c|c|c|}
\hline & 55 & 400 & & $54-55$ & $\mathrm{Al}-95$ & 1.033 & 0.262061 & 0.277472 \\
\hline \multirow{4}{*}{ Lateral 8} & 56 & 250 & & $26-56$ & $\mathrm{Al}-95$ & 0.1666 & 0.324981 & 0.344092 \\
\cline { 2 - 9 } & 57 & 250 & & $56-57$ & $\mathrm{Al}-95$ & 0.583 & 0.052223 & 0.055294 \\
\hline \multirow{4}{*}{ Lateral 9 } & 58 & 630 & & $26-58$ & $\mathrm{Al}-95$ & 0.3 & 0.183411 & 0.194197 \\
\cline { 2 - 9 } & 59 & 250 & $58-59$ & $\mathrm{Al}-95$ & 1.4 & 0.09438 & 0.09993 \\
\cline { 2 - 9 } & 61 & 400 & & $60-61$ & $\mathrm{Al}-95$ & 1.6 & 0.366823 & 0.388394 \\
\cline { 2 - 9 } & 62 & 250 & $61-62$ & $\mathrm{Al}-95$ & 1.166 & 0.44054 & 0.46644 \\
\hline
\end{tabular}

\section{APPENDIX B}

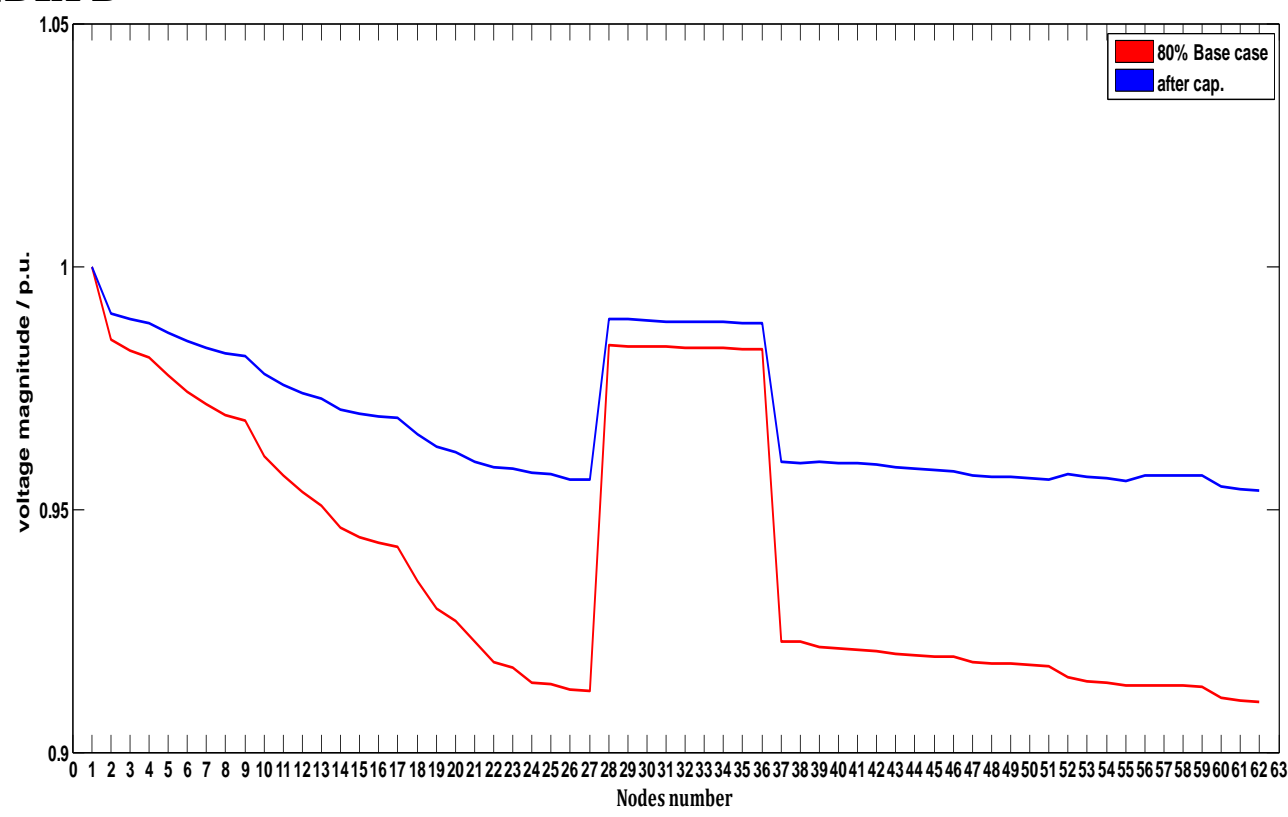

Figure (7) the voltage levels improvements

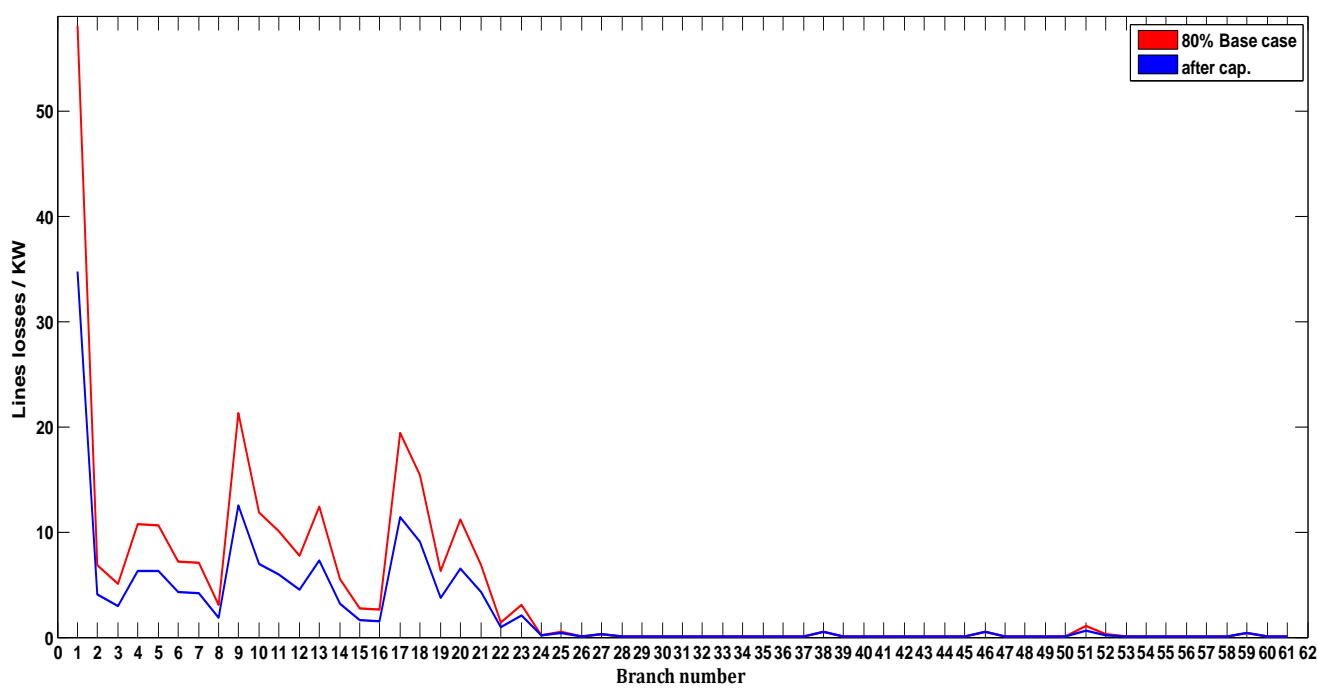

Figure (8) the active power losses improvements 


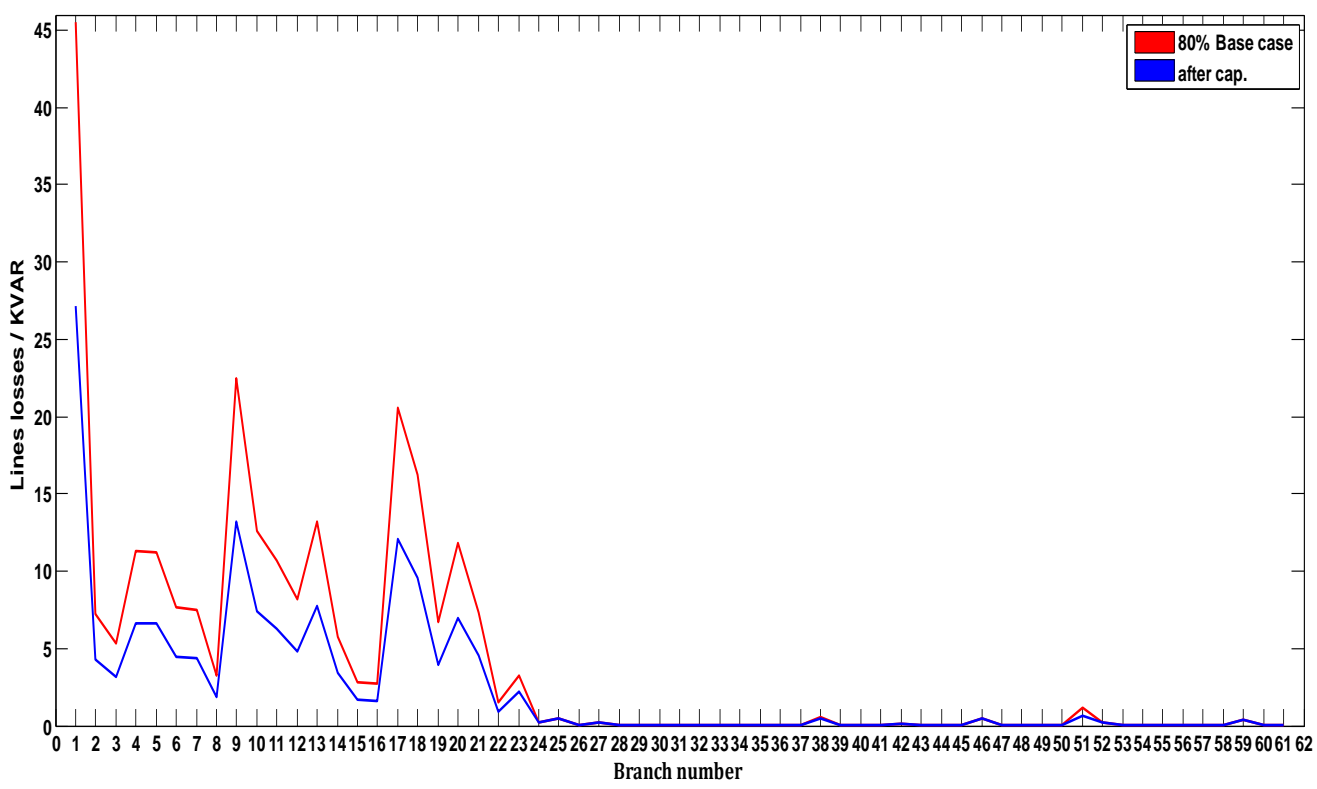

Figure (9) the reactive power losses improvements 